\title{
INFLUÊNCIA DE FATORES FISIOLÓGICOS DE PLANTAS-MATRIZES E DE ÉPOCAS DO ANO NO PEGAMENTO DE DIFERENTES MÉTODOS DE ENXERTIA DO UMBUZEIRO ${ }^{1}$
}

\author{
FRANCISCO PINHEIRO DE ARAÚJO² \& MANOEL TEIXEIRA DE CASTRO NETO³
}

\begin{abstract}
RESUMO - Com o objetivo de verificar a influência de fatores fisiológicos das plantas-matrizes de umbuzeiro (Spondias tuberosa Arruda.), as épocas de realização e os métodos de enxertia, sobre o pegamento de enxertos desta espécie, foram conduzidos cinco experimentos sob condições de viveiro, na Embrapa Semi-Árido, em Petrolina-PE. Os experimentos foram instalados nos meses de janeiro, março, maio, julho e setembro de 1998 . O delineamento utilizado foi em blocos ao acaso, com três tratamentos e oito repetições. Os tratamentos foram: garfagem em fenda cheia e à inglesa simples e borbulhia em " $\mathrm{T}$ " invertido. Os garfos foram colhidos de acordo com o ciclo fenológico das plantas-matrizes, correspondendo às fases de crescimento vegetativo, reprodutivo e de dormência, quando então se realizaram as avaliações dos fatores fisiológicos. Os fatores fisiológicos (fotossíntese, potencial hídrico e condutância estomática), observados na planta-matriz, nas diferentes fases fenológicas, não influenciaram o índice de pegamento dos diferentes métodos de enxertia. Os métodos de enxertia por garfagem em fenda cheia e à inglesa simples apresentaram maiores índices médio de pegamento, de 97,1 e 92,4\%, respectivamente. O material vegetativo (garfos) colhido nas diferentes fases fenológicas da planta-matriz não afetou o índice de pegamento do processo da enxertia, o que amplia a oferta de mudas ao longo do ano devido à oferta de material propagativo.
\end{abstract}

Termos para indexação: Spondias tuberosa, enxertia, propagação.

\section{THE INFLUENCE OF PHYSIOLOGICAL FACTORS ON GRAFTING OF UMBÚ AT DIFFERENT TIME OF THE YEAR ${ }^{1}$}

\begin{abstract}
With the objective of verifying the influence of mother plant physiological factors, grafting timing and methods of umbu trees (Spondias tuberosa Arruda) on grafting success rates, five experiments were carried out under nursery conditions at Embrapa Semi-Arid, Petrolina, Pernambuco State, Brazil. The experiments were installed in January, March, May, July and September 1998. A randomized complete-block design was used with three treatments and eight repetitions. The treatments were: cleft and whip grafting and inverted "T" budding. The grafts were collected according to the mother plant phenological cycle corresponding to the vegetative, reproductive dormancy stages, when the evaluations of the physiological factors were performed. The physiological factors (photosynthesis, water potential, and stomatal conductance) of the mother plants at the different phenological stages did not affect the rate of grafting success rates. The clef and whip grafting yielded average success rates of 97,1 and $92,4 \%$, respectively. The grafts harvested at the different phenological stages of the mother plant, did not affect the rate of success of the grafting methods, what extends the offer of nursery plants along the year, due to availability of grafts
\end{abstract}

Index Terms: Spondias tuberosa, grafting e propagation

\section{INTRODUÇÃO}

O umbuzeiro pertence à família Anacardiaceae. Em seu habitat, estendese através das áreas de caatinga do Nordeste brasileiro, e seu extrativismo ocupa um lugar de destaque na composição da renda familiar dos agricultores pelo seu expressivo valor comercial. Segundo Santos (1998), o negócio agrícola da coleta, beneficiamento e comercialização dos frutos do umbu situa-se em torno de 6 milhões de reais/ano.

Em relação ao mecanismo fisiológico de resistência à seca, alguns estudos têm sido realizados para explicar tal mecanismo. Ferri (1955), Ferri \& Labouriau (1952), Oliveira \& Labouriau (1961), Lima Filho \& Silva (1998) e, mais recentemente, Lima Filho (2001) concordam que o umbuzeiro exerce rígido controle sobre o seu estado hídrico e que a abscisão foliar anual do umbuzeiro ocorre mesmo quando a planta é cultivada em regiões úmidas com uma boa hidratação nas folhas.

A época de realização e os métodos de enxertia encontram-se entre os fatores externos que afetam ou que podem afetar o pegamento dos enxertos. Normalmente, espécies lenhosas caducas, como as frutíferas de clima temperado, apresentam ótimos índices de pegamento quando os enxertos são realizados em período de repouso vegetativo (Hartmann et al., 1990; Fachinello et al., 1994).

Estudos referentes às melhores épocas e métodos de enxertia têm sido realizados com outras espécies, como o conduzido por Gonzaga Neto (1982), que recomenda os meses de agosto e setembro como os mais propícios para a enxertia em goiabeira (Psidium guajava L.), muito embora, Gama et al. (1989) tenham identificado o mês de maio como a melhor época para a enxertia da mesma cultura. Em relação aos métodos de enxertias, Pinheiro et al. (1970) recomendam o método de garfagem em fenda cheia para mangueira (Mangifera indica L). Ledo \& Fortes (1991) relatam que as garfagens em fenda cheia e inglesa simples são os métodos recomendados para gravioleira (Annona muricata) e Holanda Neto et al. (1996) recomendam as garfagens no topo em fenda cheia e à inglesa simples para enxertia em cajueiro-anão-precoce.

Baseado no conhecimento existente, Pedrosa et al. (1991) relatam que a borbulhia em janela aberta é o método de enxertia recomendado para o umbuzeiro. Nascimento et al. (1993) ressaltam que produção de mudas de umbuzeiro em escala comercial deve ser feita através da garfagem no topo em fenda cheia. Os autores realizaram as enxertias em apenas uma fase do estádio fenológico da planta-matriz do umbuzeiro, o que limita muito a disponibilidade de garfos para a produção de mudas.

A necessidade de ampliar-se o período de coleta de garfos, para um maior fornecimento de mudas, é uma das prioridades da pesquisa. $\mathrm{O}$ presente trabalho tem como objetivo avaliar a influencia de fatores fisiológicos das plantas-matrizes de umbuzeiro (Spondias tuberosa Arruda), as épocas de realização e os métodos de enxertia sobre o pegamento dos enxertos.

\section{MATERIAL EMÉTODOS}

O trabalho foi realizado com o umbuzeiro (Spondias tuberosa Arruda) na Embrapa Semi-Árido, situada a $45 \mathrm{~km}$ de Petrolina-PE. Conforme classificação de Köeppen, o clima local é classificado como semiárido quente BSwh', sendo as coordenadas geográficas $09^{\circ} 09^{\prime}$ de latitude Sul e $40^{\circ} 22^{\prime}$ de longitude Oeste, e a altitude de $365 \mathrm{~m}$. Os dados climáticos observados ao longo de 33 anos mostram que a temperatura média anual é de $26,3^{\circ} \mathrm{C}$, com média mínima de $20,5^{\circ} \mathrm{C}$, e média máxima de $31,6^{\circ} \mathrm{C} ; 61 \%$ de umidade relativa do ar e precipitação média anual de 570 $\mathrm{mm}$.

\footnotetext{
1 (Trabalho 144/2001). Recebido: 14/09/2001. Aceito para publicação: 10/10/2002.

Parte da Dissertação de Mestrado do primeiro autor.

2 Engo ${ }^{\circ}$ M.Sc., Embrapa Semi-Árido, C.P. 23, CEP 56300-970 Petrolina-PE. E-mail: pinheiro@cpatsa.embrapa.br

3 Eng', Ph.D, Embrapa Mandioca e Fruticultura, C.P. 007, CEP 44380-000, Cruz das Almas-BA
} 
Foram estudados três métodos de enxertia: garfagem no topo em fenda cheia ( T1 ), garfagem no topo à inglesa simples ( T2 ) e borbulhia em " $T$ " invertido ( T3 ).

O estudo foi composto por cinco experimentos, cada um representando uma época de enxertia (janeiro, março, maio, julho e setembro de 1998). O delineamento empregado foi em blocos ao acaso, utilizandose de três tratamentos (métodos de enxertia), com oito repetições para cada época.

Os porta-enxertos foram formados com sementes provenientes de uma única planta adulta da safra de 1997, de ocorrência espontânea, e receberam o enxerto aos 286 dias contados da semeadura quando apresentavam uma espessura média de 0,6 a $0,8 \mathrm{~cm}$. Os garfos e borbulhas (semilenhosos), sempre do ano anterior, tinham idade média dos tecidos de 12 meses.

As plantas das quais se retiraram os enxertos e se avaliaram as características fisiológicas, foram propagadas vegetativamente. Estas plantas-matrizes tinham sete anos de idade e fazem parte do Banco Ativo de Germoplasma de Umbu da Embrapa Semi-Árido. Em cada época de enxertia, foi utilizada uma planta do acesso para as avaliações das características fisiológicas e fornecimento do enxerto.

As enxertias e as avaliações das características fisiológicas foram realizadas nas distintas fases fenológicas, caracterizadas pela fase de crescimento vegetativo, reprodutivo e o estádio de dormência (Tabela 1$)$

TABELA 1 - Comportamento da fenologia do umbuzeiro nas épocas das enxertias e das avaliações fisiológicas. Petrolina-PE, 1998

\begin{tabular}{|c|c|}
\hline Meses & Descrição fenológica \\
\hline Janeiro & $\begin{array}{l}\text { A planta encontrava -se em pleno vigor vegetativo, com frutos, e brotações } \\
\text { novas. Não foi observado nenhum tipo de pilosidade na planta. }\end{array}$ \\
\hline Março & $\begin{array}{l}\text { A planta encontrava -se em pleno vigor veg etativo, totalmente enfolhada, } \\
\text { apresentando brotações novas, sem frutos. }\end{array}$ \\
\hline Maio & $\begin{array}{l}\text { Início de repouso vegetativo e já havia perdido aproximadamente } 665 \% \text { das } \\
\text { folhas. }\end{array}$ \\
\hline Julho & A planta encontrava-se totalmente sem folhas, em pleno repouso vegetativo. \\
\hline Setembro & $\begin{array}{l}\text { A planta encontrava -se totalmente sem folhas, tendo saído do repouso } \\
\text { vegetativo, com início de crescimento de brotos florais. }\end{array}$ \\
\hline
\end{tabular}

Os processos de enxertias foram realizados de acordo com a metodologia de Hartmann et al. (1990). A avaliação do pegamento dos enxertos foi realizada aos 45 dias após a enxertia, contando-se o número de enxertos viáveis. Os tratos culturais foram realizados de acordo com a necessidade da cultura.

Nas épocas de cada enxertia, foram também realizadas as avaliações do potencial hídrico da planta, da taxa fotossintética líquida e da condutância estomática nos horários das $9 \mathrm{~h}$ e $13 \mathrm{~h}$ e foram determinadas com o medidor portátil de fotossíntese LICOR 6200 (Licor Inc, Nebraska, EUA). As leituras foram tomadas de folhas maduras expostas ao sol, situadas nas bordas da projeção da copa do umbuzeiro. Nas épocas de julho e setembro, considerou-se o valor zero para fotossintese e condutância, haja vista que a planta se encontrava totalmente sem folhas. A densidade de fluxo de fóton variou em média de 1400 a 1900 $\mu \mathrm{mol} / \mathrm{cm}^{2} / \mathrm{s}$.

O potencial hídrico foi tomado de folhas maduras expostas ao sol, situadas nas bordas da projeção da copa, pelo uso de uma bomba de pressão PMS (PMS, Utah, EUA), e nas épocas de julho e setembro foi determinado em pequenas ramificações (ramo com diâmetro médio de $2 \mathrm{~mm}$ ), e a umidade do solo foi determinada gravimetricamente, amostrando-se três pontos eqüidistantes na projeção da copa, nas profundidades de 0-20, 20-40 e 40-60 cm, utilizando um trado tubular de ferro galvanizado com $3,8 \mathrm{~cm}$ de diâmetro.

Os fatores do ambiente, como a umidade relativa e a temperatura do ar, foram monitorados por um higrômetro e termômetro, respectivamente, e armazenados em coletor automático de dados modelo LI-1000. Os sensores e o coletor automático de dados foram instalados no mesmo local onde se encontravam as plantas-matrizes. As precipitações pluviométricas foram coletadas na Estação Experimental de Manejo da Caatinga da Embrapa Semi-Árido, local onde se realizaram os experimentos.

As análises estatísticas foram realizadas para avaliar as diferenças entre os métodos de enxertias, em cada época e conjuntamente, considerando épocas, métodos e a interação métodos versus épocas como efeitos fixos. No caso da interação métodos versus épocas, fez-se a decomposição dos efeitos, avaliando-se as diferenças entre os métodos em cada época, de acordo com recomendações de Banzatto \& Kronka (1989).

Os índices de pegamento dos enxertos foram submetidos à transformação angular do arco-seno da raiz da proporção $(X=\operatorname{arco}-$ seno $\sqrt{ } \%)$, de acordo com recomendações de Snedecor \& Cochran (1974). A significância entre o efeito dos métodos de enxertia foi determinada pelo teste "F" e, nas comparações de média, utilizou-se o teste de Tukey, a $5 \%$.

Para as análises de correlações, utilizou-se o método de " forward selection” (Draper \& Smith 1966). Neste método, a ordem de inserção de variáveis é determinada pelos coeficientes de correlação parcial. Os coeficientes de correlações simples, entre o índice de pegamento dos enxertos e as características fisiológicas da planta-matriz e fenológicas dos porta-enxertos, foram testados utilizando o teste " $t$ " de Student, a 5\%, com o objetivo de verificar o nível de significância.

\section{RESULTADOSE DISCUSSÃO}

As diferentes fases fenológicas das plantas-matrizes não alteraram o índice de pegamento dos enxertos. Isto amplia o período de coleta de garfos, o que pode melhorar a oferta de mudas ao longo do ano.

Os índices de pegamento dos enxertos, em todas as épocas estudadas (Tabela 2), superaram os valores encontrados por Pedrosa et al. (1991), ou seja, 33\%, 30\% e 16\% para os métodos de garfagem à inglesa simples, fenda cheia e borbulhia em " $\mathrm{T}$ " invertido, respectivamente. Os autores não encontraram diferenças significativas entre as garfagens e a borbulhia em " $T$ " invertido, apesar de terem trabalhado com a mesma espécie e sob condições de viveiro.

Em todas as épocas estudadas, não houve diferenças significativas entre as enxertias de garfagens, no entanto, foram significativamente superiores à borbulhia. A média de enxertos viáveis, 97,1\%, para a garfagem em fenda cheia, aliada à facilidade de execução deste método, permite indicá-lo como o melhor para o umbuzeiro, independentemente da fenologia e dos fatores fisiológicos, apesar de não ter apresentado diferenças significativas em relação à garfagem à inglesa simples (Tabela 2).

TABELA 2 - Percentagem de pegamento de enxertos em umbuzeiro em função da época do ano e dos métodos de enxertia. Petrolina- PE, 1998.

\begin{tabular}{|c|c|c|c|}
\hline \multirow{3}{*}{$\begin{array}{l}\text { Épocas de } \\
\text { Enxertia }\end{array}$} & \multicolumn{3}{|c|}{ Métodos de Enxertias (\%) } \\
\hline & \multicolumn{2}{|c|}{ Garfagens } & Borbulhia \\
\hline & Fenda Cheia & Inglesa Simples & T Invertido \\
\hline Janeiro & 94,6 a A & 85,7 a A & $53,5 \mathrm{bAB}$ \\
\hline Março & 96,4 a A & 96,4 a A & $51,7 \mathrm{bAB}$ \\
\hline Maio & 96,4 a A & 87,4 a A & $67,8 \mathrm{bA}$ \\
\hline Julho & $98,2 \mathrm{a} A$ & 94,6 a A & $35,7 \mathrm{~b} \quad \mathrm{~B}$ \\
\hline Setembro & $100 \mathrm{aA}$ & $98,2 \mathrm{aA}$ & $67,8 \mathrm{bA}$ \\
\hline Média & $97,1 \mathrm{a}$ & $92,4 \mathrm{a}$ & $55,3 \mathrm{~b}$ \\
\hline
\end{tabular}

Valores seguidos pela mesma letra minúscula na linha e pela mesma letra maiúscula na coluna não diferem entre si, pelo teste de Tukey, a 5\% de probabilidade. 
Nas avaliações da taxa fotossintética líquida, observou-se que a mais alta taxa foi no mês de janeiro, diminuindo sensivelmente nos meses seguintes, atingindo zero em 17 de março e não mais voltando a atingir valores superiores a $1 \mathrm{mmol} \mathrm{de} \mathrm{CO}_{2} / \mathrm{m}^{2} / \mathrm{s}$ (Figura 1 ). Este comportamento, em grande parte, reflete a disponibilidade de água para a planta. A maior concentração de chuva foi no mês de janeiro e fevereiro, com chuvas reduzidas em março e sem nenhuma chuva em abril (Figura 2). Neste período de janeiro a março, a planta encontrava-se em plena atividade fisiológica e consumia bastante água, o que pode ter contribuído para uma queda de água disponível no solo neste mesmo período (Figura 3).

A umidade do solo, via mecanismo de potencial hídrico ou déficit hídrico, pode não apenas afetar a taxa fotossintética, mas também provocar redução da divisão celular dos tecidos meristemáticos da planta, afetando seu crescimento (Fachinello et al.,1994).

Observa-se na Figura 3 alta disponibilidade de água durante o período de janeiro a fevereiro, estando próxima à capacidade de campo. Contudo, após o mês de fevereiro, a umidade do solo permaneceu próxima ou abaixo do ponto de murcha permanente.

Como a reserva natural para o abastecimento de água da planta é o solo, o teor de umidade afeta diretamente o potencial hídrico da planta. Neste sentido, observações do potencial hídrico da planta (Figura 4) mostraram valores mais altos para os meses de janeiro e fevereiro, com uma progressiva diminuição após estes meses. Diferenças no potencial hídrico das folhas entre $9 \mathrm{~h}$ e $13 \mathrm{~h}$ devem ser maiores para os períodos de boa umidade do solo e mínimas para os períodos de déficit hídrico (Hsiao, 1973). Entretanto, Morgan (1984), revisando o efeito do ajustamento osmótico e potencial hídrico sobre as plantas, comenta que as plantas superiores podem aumentar seu potencial hídrico sob condições de déficit hídrico. Isto causaria o potencial hídrico das $13 \mathrm{~h}$ ser superior ao potencial das $9 \mathrm{~h}$, como mostra a Figura 4.

O efeito do déficit hídrico sobre mecanismo estomatal foi demonstrado por Boyen (1970), Castro Neto (1991) e Salisbury \& Ross (1992). Entretanto, o déficit hídrico pode afetar a taxa fotossintética mediante mecanismo não estomático (Berry \& Dawnton, 1982; Krieg, 1983).

Os estudos conduzidos sobre o comportamento fotossintético do umbuzeiro são raros. Neste trabalho, os dados de fotossíntese e condutância estomática indicam que, inicialmente, durante a época das chuvas, a fotossíntese, tanto no horário das 9 horas como às 13 horas, foi controlada por um mecanismo estomático devido à redução da taxa fotossintética ser acompanhada por uma diminuição da condutância estomática. Contudo, após o término do período das chuvas (Figura 2), verificou-se um esgotamento da água disponível no solo (Figura 3), levando-o a atingir seu ponto de murcha permanente.

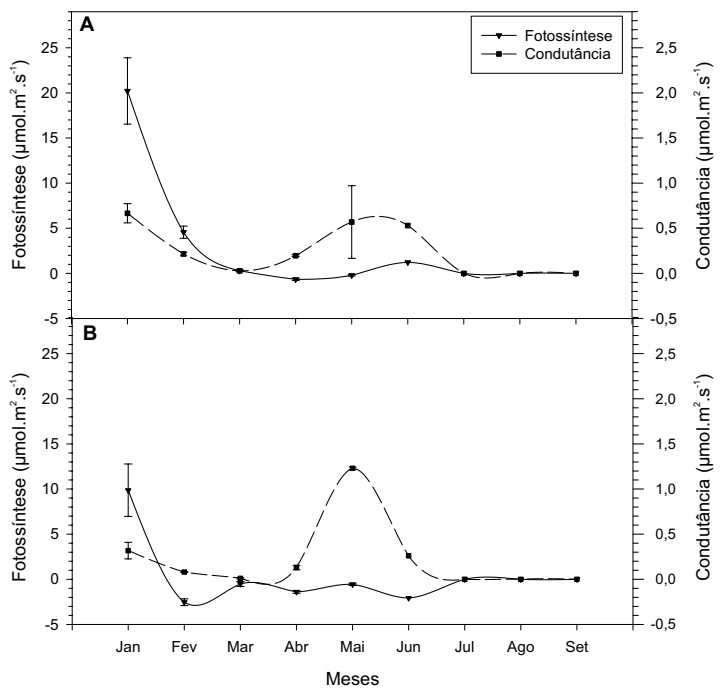

FIGURA 1 - Comportamento da fotossíntese e condutância estomática do umbuzeiro às $9 \mathrm{~h}$ (Gráfico A) e às $13 \mathrm{~h}$ (Gráfico B). As barras representam o desvio-padrão para cada época de avaliação Petrolina-PE, 1998
Os dados obtidos sugerem que um mecanismo não estomático pode ser o principal responsável pela inibição da fotossíntese do umbuzeiro, sob condições de déficit hídrico. Esta sugestão parece provável devido ao aumento da condutância estomática não provocar elevação ou aumento da taxa fotossintética do umbuzeiro (Figura 1). Nesta situação, provavelmente, tenham ocorrido danos ao sistema de enzimas do aparelho fotossintético, ou o estresse hídrico foi capaz de afetar a atividade das membranas dos cloroplastos, como sugerem os autores Krieg (1983) e Berry \& Downton (1982); apesar disto, o percentual da enxertia não foi afetado (Tabela 2). Para Medina et al. (1998), o decréscimo da fotossíntese em laranjeiras foi ocasionado pelo aumento do déficit de pressão de vapor e da temperatura ambiente.

Em relação ao controle estomatático, este mecanismo é o mais eficiente para o controle de perdas de água das plantas, embora a planta tenha de enfrentar o dilema de ter de economizar água e absorver $\mathrm{CO}_{2}$ pelo mesmo caminho, isto é, os estômatos (Salisbury \& Ross, 1992). Nos dados deste trabalho, observa-se que, durante o período das chuvas, a condutância estomática apresentava-se baixa, sugerindo, assim, um controle estomatal para a economia de água.

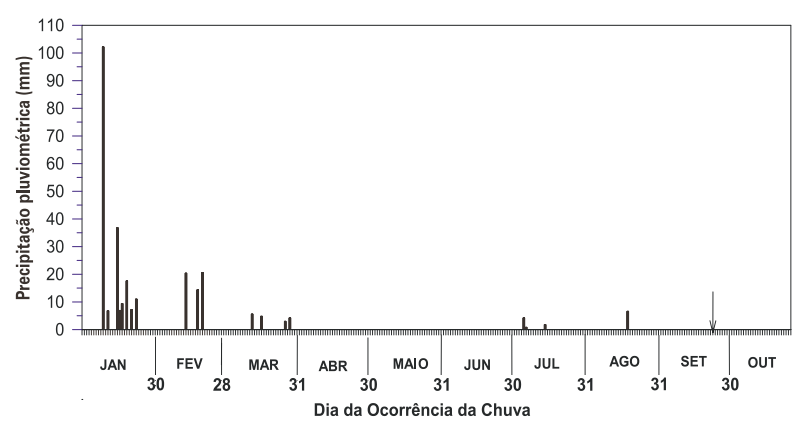

FIGURA 2 - Precipitações pluviométricas durante o período das enxertias e monitoramento das plantas de umbuzeiro. Petrolina- PE, 1998.

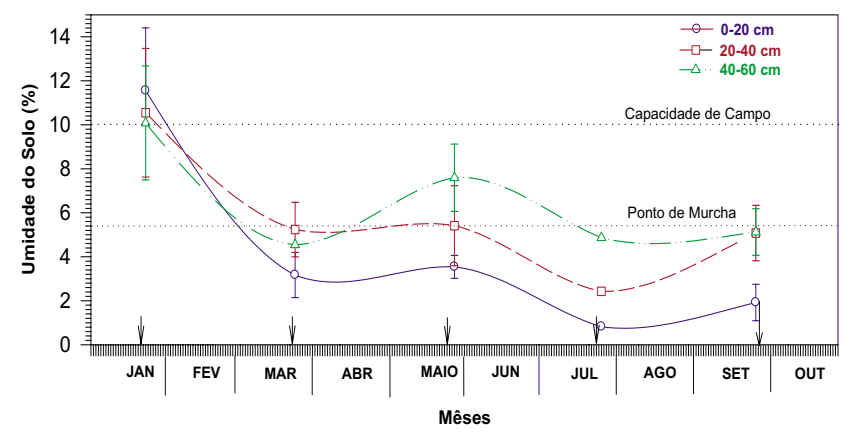

FIGURA 3 - Teores de umidade do solo para diferentes profundidades durante o período das enxertias e monitoramento do umbuzeiro. As barras representam o desvio-padrão para cada época de avaliação. Petrolina-PE, 1998.

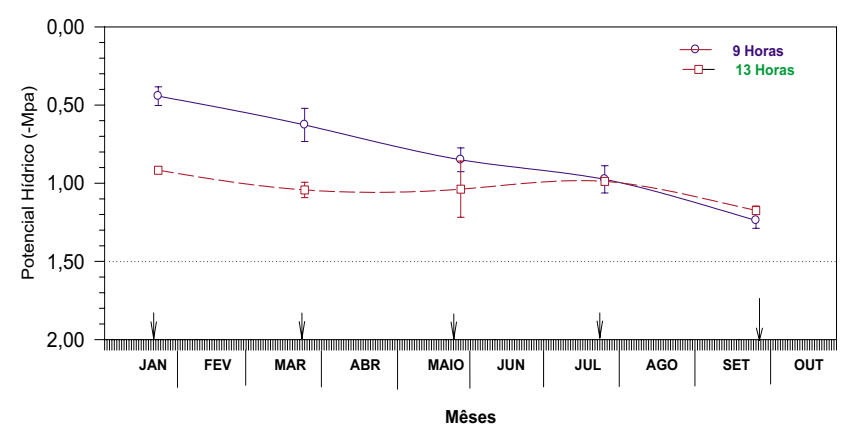

FIGURA 4 - Potencial hídrico do umbuzeiro durante o período das enxertias e monitoramento do umbuzeiro. As barras representam o desvio-padrão para cada época de avaliação. Petrolina-PE, 1998. 


\section{CONCLUSÕES}

1. Os fatores fisiológicos, fotossíntese, potencial hídrico, resistência e condutância estomática, observados na planta-matriz, nas diferentes fases fenológicas, não influenciaram o índice de pegamento dos diferentes métodos de enxertia do umbuzeiro.

2. Os métodos de enxertia por garfagem em fenda cheia e à inglesa simples apresentaram maiores índices de pegamento, em média 97,1 e $92,4 \%$, respectivamente.

3. O material vegetativo (garfos) obtido nas épocas de coleta (fases fenológicas) não afetou a porcentagem de pegamento das enxertias realizadas pelos métodos de garfagem em fenda cheia e à inglesa simples, o que amplia a oferta de mudas ao longo do ano.

\section{REFERÊNCIASBIBLIOGRÁFICAS}

BANZATTO, D. A.; KRONKA, S. do N. Experimentação agrícola. Jaboticabal: FUNEP/UNESP-FCAV, 1989. 247p.

BERRY, J. A.; DOWNTON, W. J. S. Environmental regulation of photosynthesis. In: GOVINDJEE, D., (Ed.). Photosynthesis: development, carbon metabolism, and plant productivity. New York: Academic Press, 1982. v. 2, p. 263-343. (Cell Biology: A Series of Monographs).

BOYEN, J. S. Differing sensitivity of photosynthesis to low leaf water potentials in corn and soybean. Plant Physiology, Bethesda, v. 46,p. 236-239,1970.

CASTRO NETO, M. T. de. Dry matter partitioning of bean (Phaseolus vulgaris L.) and cowpea (Vigna unguiculata (L.) Walp.) under water deficit conditions. 1991. 171f. Thesis (Ph.D. in Plant Physiology). University of Arizona, Tucson, 1991.

DRAPER, N. R.; SMITH, H. Applied regression analysis. New York: J. Wiley, 1966. 407p.il.

FACHINELLO, J. C.; HOFFMANN, A.; NACHTIGAL, J. C.; KERSTEN, E.; FORTES, G. R. de. L. Propagação de plantas frutíferas de clima temperado. Pelotas: UFPEL, 1994. 179p. il.

FERRI, M. G. Contribuição ao conhecimento da ecologia do cerrado e da caatinga: estudo comparativo da economia d'água de sua vegetação. São Paulo: Universidade de São Paulo, 1955. 170p. (USP.Boletim; 195. Botânica; 12).

FERRI, M.G.; LABOURIAU, L. G. Water balance of plants from the "caatinga". I Transpiration of some of the most frequent species of the "caatinga" of Paulo Afonso (Bahia) in the roing slason. Revista Brasileira de Biologia, Rio de Janeiro, v. 12, n.3, p. 301-312, out. 1952.

GAMA, F. S. N. da; KIST, H. G.; ACCORST, M. R. Efeito da época de enxertia e do tipo de garfo sobre o pegamento de enxertos de goiabeira (Psidium guajava L.). Revista Brasileira de Fruticultura, Cruz das Almas, v. 11, n. 2, p .45-47, 1989.

GONZAGA NETO, L. Estudos de métodos de produção de porta-enxerto e de enxertia da goiabeira (Psidium guajava L.). 1982. 51f. Dissertação (Mestrado) Unversidade Federal de Viçosa, Viçosa.

HARTMANN, H. T.; KESTER, D. E. ; DAVIES JUNIOR, F. T. Plant propagation: principles and practices. 5.ed. Englewood Cliffs: Prentice-Hall, 1990. 647p. il.
HOLANDA NETO, J. P. de; HENRIQUE NETO. D. ; CARDOSO, E. de A, PIRES, G. de S. Avaliação de métodos de enxertia em cajueiroanão-precose sob condições de campo. Revista Brasileira de Fruticultura, Cruz das Almas, v. 18,n. 2, p. 171, ago. 1996.

HSIAO, T. C. Plant responses to water stress. Annual Review of Plant Physiology, Palo Alto, v. 24, p. 519-570, 1973.

KRIEG, D. R. Whole plant responses to water deficits: carbon assimilation and utilization. In: TAYLOR, H. M.; JORDAN, W. R. ; SINCLAIR, T. R. (Ed.). Limitations to efficient water use in crop production. Wisconsin: American Society of Agronomy, 1983. p. 319-374.

LEDO, A da S.; FORTES, J. M. Avaliação de métodos de enxertia para a gravioleira em Viçosa-MG. Revista Brasileira de Fruticultura, Cruz das Almas, v. 13, n.1, p. 63-66, out. 1991.

LIMA FILHO, J. M. P.; SILVA, C. M. M. de S. Aspectos fisiológicos do umbuzeiro. Pesquisa Agropecuária Brasileira, Brasília, v. 23, n. 10, p. 1091-1094, out. 1998.

LIMA FILHO, J. M. P. Internal water relations of the umbu tree under semi-árid condicions Revista Brasileira de Fruticultura, Jaboticabal, v. 23, n.3, p. $518-521$,dez. 2001

MEDINA, C. L.; MACHADO, E. C.; PINTO, J. M. Fotossíntese de laranjeira "Valência" enxertada sobre quatro porta-enxertos e submetida à deficiência hídrica. Bragantia, Campinas, v. 57, n. 1, p.1-14, 1998.

MORGAN, J. N. Osmoregulation water stress in higher plants. Annual Review of Plant Physiology, Palo Alto, v. 35, p. 299-319,1984.

NASCIMENTO, C. E. de S.; OLIVEIRA, V. R. de; NUNES, R. F. de M. ; ALBU-QUERQUE, T. C. S. de. Propagação vegetativa do umbuzeiro. In: CONGRESSO FLORESTAL PANAMERICANO, 1.; CONGRESSO FLORESTAL BRASILEIRO, 7., 1993, Curitiba-PR. Floresta para o desenvolvimento: política, ambiente, tecnologia e mercado - Anais. Curitiba: SBS/SBEF, 1993. v. 2, p. 454-456.

OLIVEIRA, J. G. B. de; LABOURIAU, L. G. Transpiração de algumas plantas de caatinga aclimatadas no Jardim Botânico do Rio de Janeiro, I. Comportamento de caesalpinia pyramidalis tull., de Zizypus joazeiro Mart., de Jatropha ophyllacantra Mulel. Arg. E de Spondias tuberosa Arruda. Anais da Academia Brasileira de Ciência, Rio de Janeiro, v. 33, n. 3/4, p. 351-373, 1961.

PEDROSA, A. C. ; LEDERMAN, I. E. ; BEZERRA, J. E. F. ; DANTAS, A. P.; GONZAGA NETO, L. Métodos de enxertia do umbuzeiro (Spondias tuberosa Arr. Cam) em viveiro. Revista Brasileira de Fruticultura, Cruz das Almas, v. 13, n.1, p. 59-62, out. 1991

PINHEIRO, R.V.R.; ANDERSEN, O.; FORTES, J.M. Comparação de modalidades de enxertia na propagação da mangueira (Mangifera indica L.) Revista Ceres, Viçosa, v. 17, n. 93, p. 63-66 jul./set 1970.

SALISBURY, F. B.; ROSS, C. W. The photosynthesis-transpiration compromise. In: SALISBURY, F. B. ; ROSS, C. W. Plant physiology. 4.ed. California: Wadsworth, 1992. p. 66-92.

SANTOS, C. A . F.; Relação entre caracteres de produção do umbuzeiro com características químicas e teor de água do solo Revista Brasileira de Fruticultura, Cruz das Almas, v. 20, n. 2, p. 206-212, ago. 1998.

SNEDECOR, G. W.; COCHRAN, W. G. Statistical methods. Ames: Iowa 